\section{Acknowledgements}

This work was partly supported by MigrosGenossenschafts-Bund Zurich, Switzerland. The herbs and vegetables samples were a gift of J. Carl Fridlin Gewürze AG (Hünenberg, Switzerland). Most of this work has been presented at the conference 'Chemical Reactions in Foods IV' (Prag, September 2000) and has been reprinted with permission of the publisher from Czech J. Food Sci. 2000, 18, 17-19.

Received: May 2, 2002

[1] H. Guth, W. Grosch, Fat. Sci. Technol. 1991, 93, 249.

[2] J.A. Sarelse, K.B. de Roos, C.B. Kanner, P.C. Burgers, J. Kloosterman, in 'Trends in Flavour Research', Eds. H. Maarse, D.G. van der Heij, Elsevier Science, Amsterdam, 1994, p. 373.

[3] R. Pompizzi, M. Lamberti, R. Oechslin,
G.G.G. Manzardo, R. Amadò, in 'Authenticity and Adulteration of Food - the Analytical Approach', Eds. R. Amadò, R. Battaglia, Swiss Society of Food and Environmental Chemistry (SGLUC), Federation of European Chemical Societies, Food Chemistry Division, Winterthur, 1997, p. 472.

[4] R. Pompizzi, 'Furanfettsäuren als Vorläufer von Aromastoffen', ETH-Dissertation Nr. 12129, 1999.

[5] H. Guth, W. Grosch, in 'Progress in Flavour Precursors Studies', Eds. P. Schreier, P. Winterhalter, Allured Publishing Corporation, Carol Stream, 1993, p. 401.

[6] C. Masanetz, W. Grosch, Z. Lebensm. Unters. Forsch. A 1998, 206, 114.

[7] C. Masanetz, H. Guth, W. Grosch, Z. Lebensm. Unters. Forsch. A 1998, 206, 108.
[8] H. Horita, T. Hara, A. Sannai, T. Fujimori, Agric. Biol. Chem. 1985, 49, 3601.

[9] B.D. Mookherjee, R.A. Wilson, Perf. \& Flav. 1990, 15 (Jan./Feb.), 27.

[10] D.K. Larick, H.B. Hedrick, M.E. Bailey, J.E. Williams, D.L. Hancock, G.B. Garner, R.E. Morrow, J. Food Sci. 1987, 52, 245.

[11] O.A. Young, J.-L. Berdagué, C. Viallon, S. Rousset-Akrim, M. Theriez, Meat Sci. 1997, 45, 183 .

[12] D.B. Josephson, R.C. Lindsay, D.A. Stuiber, J. Agric. Food Chem. 1984, 32, 1344.

[13] H. Van den Dool, P.D. Kratz, J. Chromatog. 1962, 11, 463.

[14] I.A. Sigrist, ETH Dissertation, in preparation

[15] I.A. Sigrist, G.G.G. Manzardo, R. Amadò, in 'Biologically-active Phytochemicals in Food', Eds. W. Pfannhauser, G.R. Fenwick, S. Khokhar, Royal Society of Chemistry, Cambridge, 2001, p. 237.

\title{
Continuous Evolved Gas Analysis and Thermal Analysis in Micro-scale Roasting of Foods
}

\author{
Rainer Perren*, Roland Künzli, and Felix Escher
}

\begin{abstract}
In roasting processes of foods, non-enzymatic browning reactions lead to the formation of water and carbon dioxide. Continuous monitoring of the evolution of moisture and carbon dioxide would offer an interesting tool for determining reaction kinetics of non-enzymatic browning and optimising roasting processes. Isothermal and dynamic heating of small specimens of hazelnuts in a differential scanning calorimeter which was linked to a non-dispersive IR gas analyser presents a possibility to simulate roasting processes on a micro-scale. Formation of water and carbon dioxide was dependant on the initial moisture content of the hazelnuts, heating rate and composition of gas atmosphere (nitrogen vs. oxygen). Depending on the heating conditions, evolution of carbon dioxide is not only caused by degradation of amino acids and sugars but also by lipid oxidation.
\end{abstract}

Keywords: Evolved gas analysis · Lipid oxidation · Non-enzymatic browning · Roasting of foods · Thermal analysis

${ }^{\star}$ Correspondence: Dr. R. Perren

Institute of Food Science and Nutrition

ETH-Zentrum

$\mathrm{CH}-8092$ Zürich

Tel: : +4116327975

Fax: +4116321123

E-Mail: rainer.perren@ilw.agrl.ethz.ch

www.ethz.ch

\section{Introduction}

Roasting of nuts, cocoa, coffee etc. is carried out to develop flavour components from sugars and amino acids by the nonenzymatic browning reaction at increased temperatures. Thereby, the moisture content is decreased to below $1 \%$ and a crisp texture is developed. Non-enzymatic browing reactions at roasting temperatures of
120-200 ${ }^{\circ} \mathrm{C}$ lead to the formation of flavour and colour compounds as well as to the evolution of water and carbon dioxide [1][2]. In addition to the decarboxylation of amino acids during the Strecker degradation, carbon dioxide is formed by thermal degradation of sugars and ascorbic acid, and also by lipid oxidation [3]. Finally, pyrolysis and combustion of organic material occur at elevated temperatures. As long as a sufficient 


\section{Acknowledgements}

This work was partly supported by MigrosGenossenschafts-Bund Zurich, Switzerland. The herbs and vegetables samples were a gift of J. Carl Fridlin Gewürze AG (Hünenberg, Switzerland). Most of this work has been presented at the conference 'Chemical Reactions in Foods IV' (Prag, September 2000) and has been reprinted with permission of the publisher from Czech J. Food Sci. 2000, 18, 17-19.

Received: May 2, 2002

[1] H. Guth, W. Grosch, Fat. Sci. Technol. 1991, 93, 249.

[2] J.A. Sarelse, K.B. de Roos, C.B. Kanner, P.C. Burgers, J. Kloosterman, in 'Trends in Flavour Research', Eds. H. Maarse, D.G. van der Heij, Elsevier Science, Amsterdam, 1994, p. 373.

[3] R. Pompizzi, M. Lamberti, R. Oechslin,
G.G.G. Manzardo, R. Amadò, in 'Authenticity and Adulteration of Food - the Analytical Approach', Eds. R. Amadò, R. Battaglia, Swiss Society of Food and Environmental Chemistry (SGLUC), Federation of European Chemical Societies, Food Chemistry Division, Winterthur, 1997, p. 472.

[4] R. Pompizzi, 'Furanfettsäuren als Vorläufer von Aromastoffen', ETH-Dissertation Nr. 12129, 1999.

[5] H. Guth, W. Grosch, in 'Progress in Flavour Precursors Studies', Eds. P. Schreier, P. Winterhalter, Allured Publishing Corporation, Carol Stream, 1993, p. 401.

[6] C. Masanetz, W. Grosch, Z. Lebensm. Unters. Forsch. A 1998, 206, 114.

[7] C. Masanetz, H. Guth, W. Grosch, Z. Lebensm. Unters. Forsch. A 1998, 206, 108.
[8] H. Horita, T. Hara, A. Sannai, T. Fujimori, Agric. Biol. Chem. 1985, 49, 3601.

[9] B.D. Mookherjee, R.A. Wilson, Perf. \& Flav. 1990, 15 (Jan./Feb.), 27.

[10] D.K. Larick, H.B. Hedrick, M.E. Bailey, J.E. Williams, D.L. Hancock, G.B. Garner, R.E. Morrow, J. Food Sci. 1987, 52, 245.

[11] O.A. Young, J.-L. Berdagué, C. Viallon, S. Rousset-Akrim, M. Theriez, Meat Sci. 1997, 45, 183 .

[12] D.B. Josephson, R.C. Lindsay, D.A. Stuiber, J. Agric. Food Chem. 1984, 32, 1344.

[13] H. Van den Dool, P.D. Kratz, J. Chromatog. 1962, 11, 463.

[14] I.A. Sigrist, ETH Dissertation, in preparation

[15] I.A. Sigrist, G.G.G. Manzardo, R. Amadò, in 'Biologically-active Phytochemicals in Food', Eds. W. Pfannhauser, G.R. Fenwick, S. Khokhar, Royal Society of Chemistry, Cambridge, 2001, p. 237.

\title{
Continuous Evolved Gas Analysis and Thermal Analysis in Micro-scale Roasting of Foods
}

\author{
Rainer Perren*, Roland Künzli, and Felix Escher
}

\begin{abstract}
In roasting processes of foods, non-enzymatic browning reactions lead to the formation of water and carbon dioxide. Continuous monitoring of the evolution of moisture and carbon dioxide would offer an interesting tool for determining reaction kinetics of non-enzymatic browning and optimising roasting processes. Isothermal and dynamic heating of small specimens of hazelnuts in a differential scanning calorimeter which was linked to a non-dispersive IR gas analyser presents a possibility to simulate roasting processes on a micro-scale. Formation of water and carbon dioxide was dependant on the initial moisture content of the hazelnuts, heating rate and composition of gas atmosphere (nitrogen vs. oxygen). Depending on the heating conditions, evolution of carbon dioxide is not only caused by degradation of amino acids and sugars but also by lipid oxidation.
\end{abstract}

Keywords: Evolved gas analysis · Lipid oxidation · Non-enzymatic browning · Roasting of foods · Thermal analysis

${ }^{\star}$ Correspondence: Dr. R. Perren

Institute of Food Science and Nutrition

ETH-Zentrum

$\mathrm{CH}-8092$ Zürich

Tel: : +4116327975

Fax: +4116321123

E-Mail: rainer.perren@ilw.agrl.ethz.ch

www.ethz.ch

\section{Introduction}

Roasting of nuts, cocoa, coffee etc. is carried out to develop flavour components from sugars and amino acids by the nonenzymatic browning reaction at increased temperatures. Thereby, the moisture content is decreased to below $1 \%$ and a crisp texture is developed. Non-enzymatic browing reactions at roasting temperatures of
120-200 ${ }^{\circ} \mathrm{C}$ lead to the formation of flavour and colour compounds as well as to the evolution of water and carbon dioxide [1][2]. In addition to the decarboxylation of amino acids during the Strecker degradation, carbon dioxide is formed by thermal degradation of sugars and ascorbic acid, and also by lipid oxidation [3]. Finally, pyrolysis and combustion of organic material occur at elevated temperatures. As long as a sufficient 
gas phase exchange is maintained, these heterogeneous reactions are hardly reversible. Therefore, dynamic measurements using evolved gas analysis (EGA) to monitor the formation of water and carbon dioxide are suitable to investigate heat induced reactions during roasting processes.

In order to put optimisation of roasting processes on a kinetic basis, it is also desirable to know the kinetics of the formation of carbon dioxide during non-enzymatic browning reactions. So far, little information is available. The activation energy of the evolution of carbon dioxide during heat treatment of corn was reported to be around $107 \mathrm{~kJ} \mathrm{~mol}^{-1}$, while the activation energy of the formation of carbon dioxide in heated glucose-glycine ranged between 103 to $115 \mathrm{~kJ} \mathrm{~mol}^{-1}$ [4][5]. Usually a zero order reaction may be assumed for modelling the evolution of carbon dioxide.

Originally, most authors applied static methods for the determination of gaseous products requiring long isothermal storage periods for product enrichment. Dynamic methods are described in combination with thermal analysis. Lephardt and Fenner [6] introduced an EGA method to monitor pyrolysis and combustion processes of complex organic materials, e.g. tobacco using FTIR spectroscopy. Morgan [7] described a fast and accurate method linking thermal analysis to non-dispersive IR to determine evolution of carbon dioxide and water from minerals. Further methods for EGA were reviewed by Brown [8].

Here we present experiments with a combination of thermal analysis and EGA as a micro-scale technique to simulate roasting processes of fat-containing nuts and to determine the kinetics of non-enzymatic browning reactions during dry heating of foods.

\section{Materials and Methods}

\subsection{Raw Material and Sample Preparation}

Hazelnuts (Corylus avellana L.) of the Akcakoca cultivar were used for all experiments. To adjust the initial moisture content at different levels, nuts were either vacuumdried at $25{ }^{\circ} \mathrm{C}$ and 100 mbar or sprinkled with water under continuous mixing and equilibrated in moisture for $1 \mathrm{~h}$. Nuts were then cut with a razor blade into slices of less than $0.7 \mathrm{~mm}$ thickness. Cylindrical specimens of $3 \mathrm{~mm}$ in diameter were punched from these slices using a sharp steel tube and placed in perforated $50 \mu \mathrm{L}$ aluminium pans (Perkin Elmer, CH-Rotkreuz) for thermal and evolved gas analysis

\subsection{Equipment and Operating Conditions}

The aluminium pans were placed in a differential scanning calorimeter (DSC) (System-4, Perkin-Elmer, CH-Rotkreuz). Oxygen and nitrogen were used as purge gases. Gas flow was kept constant at $130 \mathrm{ml}$ $\mathrm{min}^{-1}$, which prevented moisture condensation in the gas flow tubes. Prior to heating, the samples were equilibrated until water evolution from the sample became minimal. Heating was either carried out by linear heating rates from 5 to $30^{\circ} \mathrm{C} \mathrm{min}{ }^{-1}$, or by a rapid temperature increase with subsequent isothermal treatment. In linear heating rate mode, DSC thermograms were recorded by using standard recording procedures.

The gas outlet of the DCS was linked to a non-dispersive IR gas analyser LI-6262 (Li-Cor Inc., Lincoln, Nebraska). $\mathrm{H}_{2} \mathrm{O}$ and $\mathrm{CO}_{2}$ were detected at $2590 \mathrm{~nm}$ and 4260 $\mathrm{nm}$, respectively. Air dried with $\mathrm{Mg}\left(\mathrm{ClO}_{4}\right)_{2}$ and freed from carbon dioxide with soda lime was used as a reference gas. The accuracy of the determination was $\pm 1 \%$ for water vapour and $\pm 0.5 \%$ for carbon dioxide [9]. The measuring frequency was $10 \mathrm{~s}^{-1}$, and the data obtained were averaged each second. The analyser was calibrated using a gas mixture containing $1039.2 \mathrm{ppm} \mathrm{CO}_{2}$ in $\mathrm{N}_{2}$ (Carbagas, $\mathrm{CH}-$ Zürich) and a dew point generator LI-610 (Li-Cor Inc., Lincoln Ne) respectively. All measurements were carried out in at least three replicates.

\section{Results and Discussion}

\subsection{Heating in Inert Atmosphere}

Fig. 1 shows the DSC thermograms of

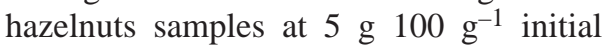
moisture content in open aluminium pans at different heating rates. At a heating rate of $30{ }^{\circ} \mathrm{C} \mathrm{min}-1$, a rapid increase in energy absorption occurred between 130 to $160{ }^{\circ} \mathrm{C}$, with a peak maximum near $140{ }^{\circ} \mathrm{C}$. Since no endothermic peak occurred in a second run (not shown in this figure), the endothermic event is interpreted as a sudden delayed water evaporation. The delay is caused most probably due to limitations in diffusive mass transfer rates. The endothermic peak decreased with decreasing heating rate indicating a more continuous development and release of water vapour. At very low rates, the endothermic peak is not visible anymore. Measurements with lower initial moisture contents gave similar results.

Moisture desorption and evolution was monitored by gas analysis as shown in Fig. 2. Maximum moisture evaporation rates were found between $127{ }^{\circ} \mathrm{C}$ and $165{ }^{\circ} \mathrm{C}$, depending on heat rate and initial moisture content. It can be seen again that at high heating rates part of water evaporation is delayed and then suddenly takes place at higher temperatures. At higher temperatures evaporation shifts more and more to water which is formed by non-enzymatic browning reactions. The evolution of this

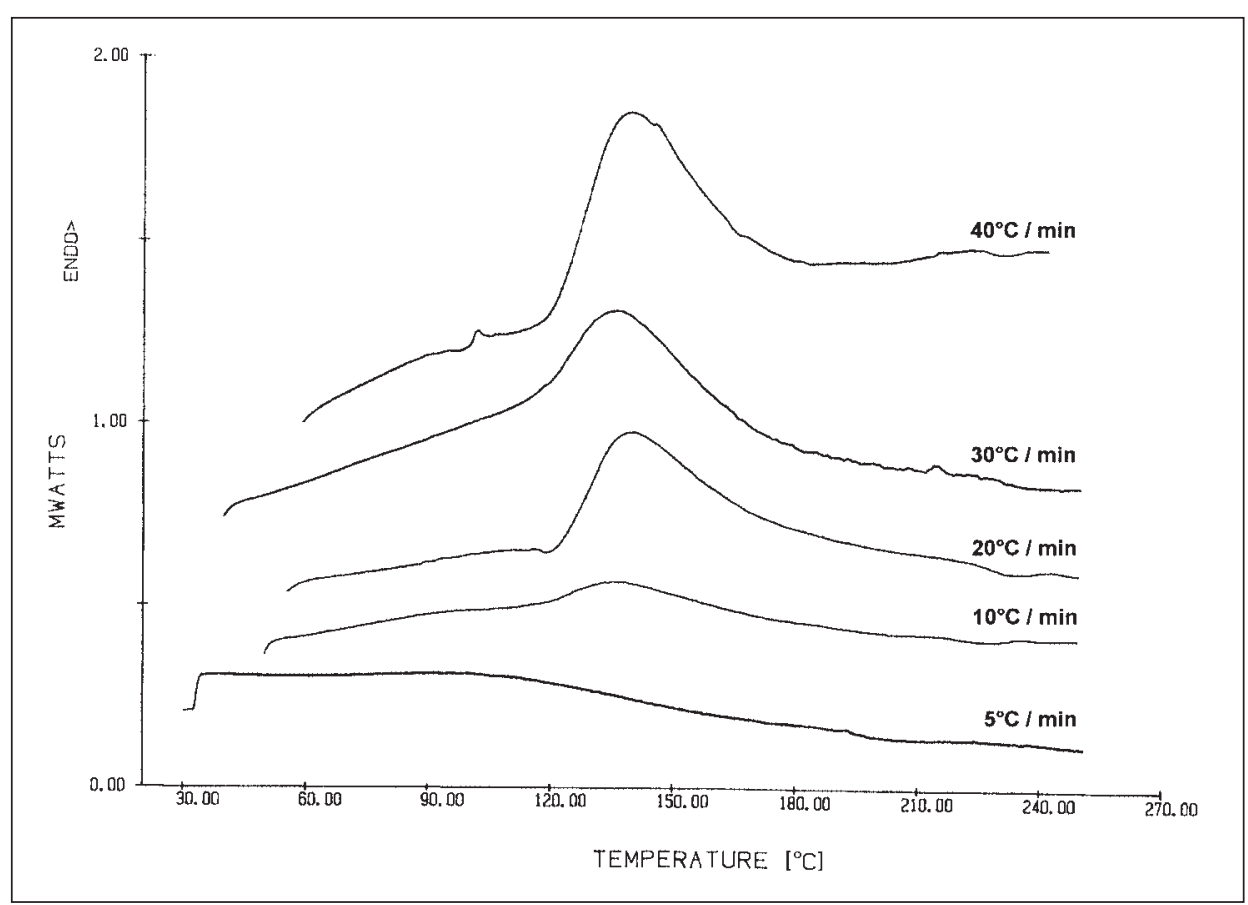

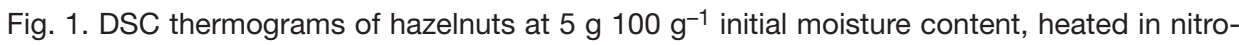
gen atmosphere at different heating rates. 


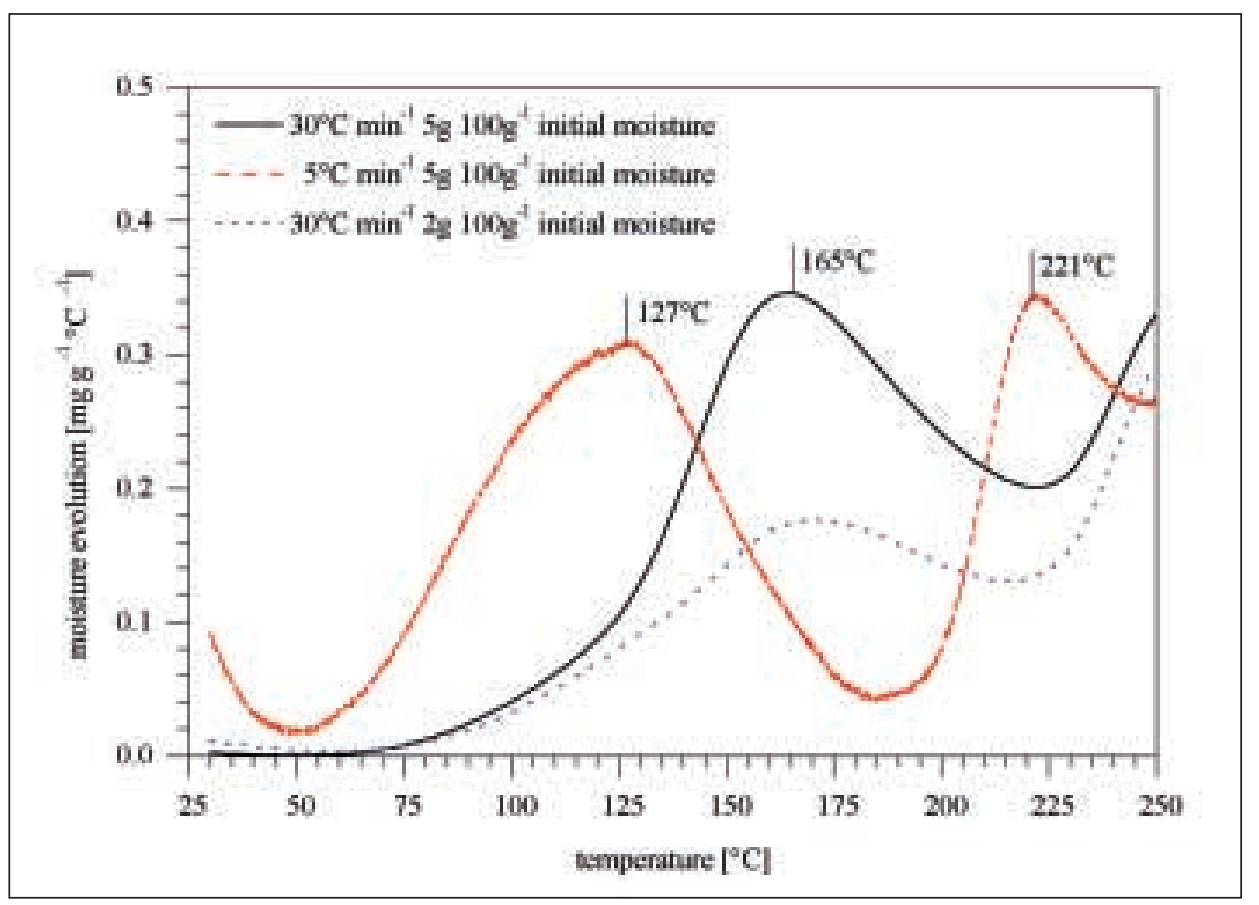

water into the gas phase is also controlled by the heating rate on one side and the diffusion rate of vapour out of the nut tissue on the other side.

Heat-induced evolution of carbon dioxide at two different heating rates and two initial moisture levels is shown in Fig. 3. Carbon dioxide evolution is the result of non-enzymatic browning reactions, in particular of the decarboxylation in the Strecker degradation. As the heating was carried in a inert gas atmosphere, development of carbon dioxide due to oxidation can be excluded. In the present experimental set-up, the rate of carbon dioxide formation seems to be much more dependent on heating rate rather than on the initial moisture content. The temporary drop of carbon dioxide evolution around $200{ }^{\circ} \mathrm{C}$ in the case of a low heating rate cannot be explained.

\subsection{Heating in Oxygen Atmosphere}

When oxygen was applied as a purge gas, a similar moisture desorption behaviour was found in principal (Fig. 4) as with inertial purge gas (Fig. 2). Interestingly, moisture evolution at heating rates of $5^{\circ} \mathrm{C}$ $\mathrm{min}^{-1}$ caused by heat-induced reactions increased rapidly at temperatures above $185^{\circ} \mathrm{C}$. Since there was an intense exothermal process monitored in the DSC analysis at the same temperature range (data not

Fig. 2. Moisture evolution from hazelnuts with two different levels of initial moisture content, heated in nitrogen atmosphere at two different heating rates.

shown), this increase in moisture evolution is attributed to auto-catalysed lipid oxidation. Heating rates higher than $5{ }^{\circ} \mathrm{C} \mathrm{min}^{-1}$ caused a considerably less intense oxidation reaction even at higher temperatures which may be explained by the time/temperature relationship of the induction period of lipid oxidation.

In Fig. 5, the evolution of carbon dioxide in oxygen and nitrogen atmospheres is compared. As for the moisture evolution in Fig. 4, the formation of carbon dioxide in oxygen atmosphere at a heating rate of $5^{\circ} \mathrm{C}$ $\mathrm{min}^{-1}$ started already at $135^{\circ} \mathrm{C}$. During further heating the decarboxylation rate increased strongly. With a heating rate of $5{ }^{\circ} \mathrm{C}$

Fig. 3. Evolution of carbon dioxide from hazelnuts with two different levels of initial moisture content, heated in nitrogen atmosphere at two different heating rates. 


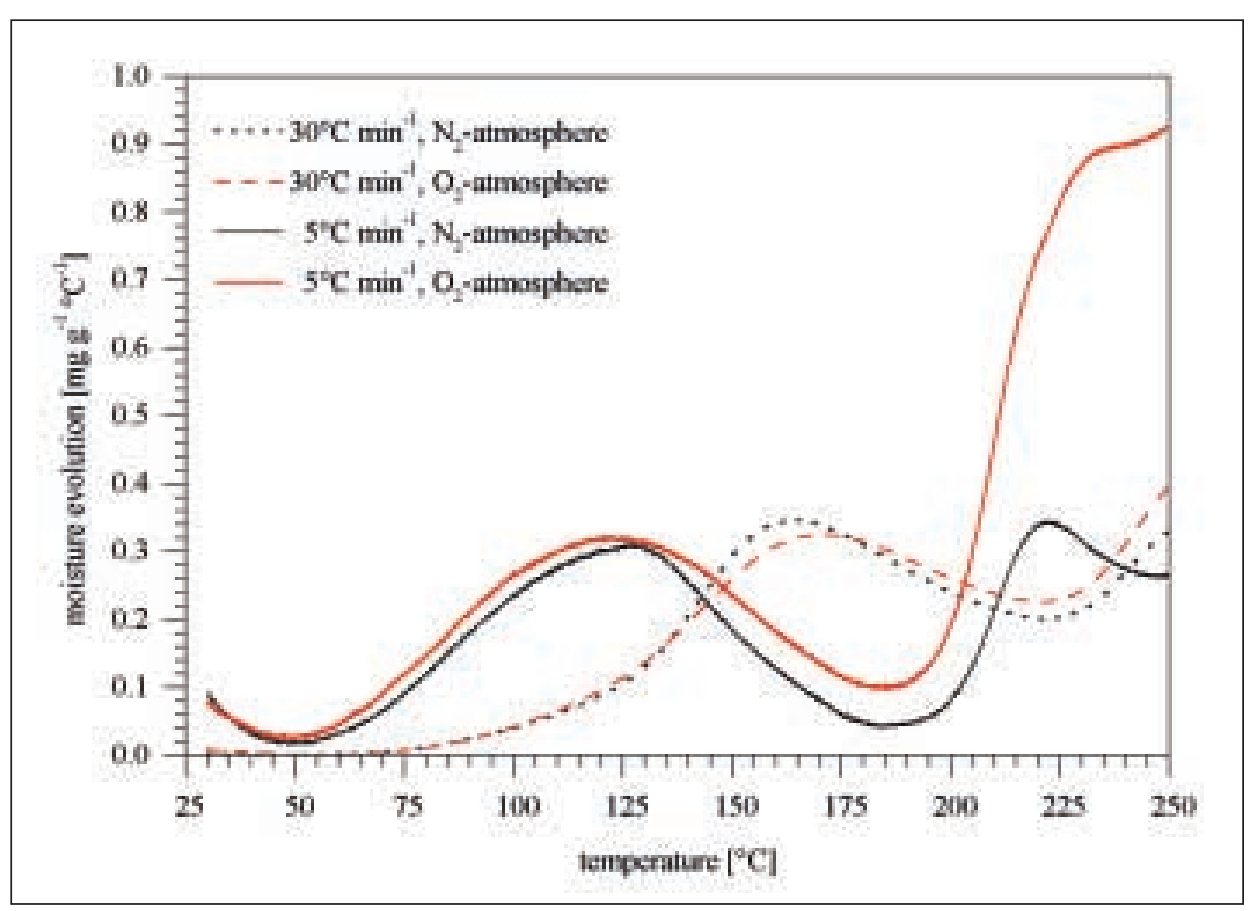

$\min ^{-1}$ in inert atmosphere carbon dioxide evolution was delayed up to $150{ }^{\circ} \mathrm{C}$. In the same way increasing the heating rate to $30{ }^{\circ} \mathrm{C} \mathrm{min}{ }^{-1}$ in both atmospheres delayed and diminished the oxidative decarboxylation reaction. Nevertheless, it becomes clear that in all cases of heating in oxygen atmosphere lipid oxidation is a reaction equally strong to that of non-enzymatic browning. Therefore, oxidation may lead to a substantial oxidative load of freshly roasted nuts even if roasting is carried out in air instead of pure oxygen.

\subsection{Reaction Kinetics of Carbon Dioxide Formation}

When oxygen is excluded from the heating experiment, carbon dioxide is formed primarily during Strecker degradation. For this situation average decarboxylation rates were determined by evolved gas analysis of DSC runs at isothermal conditions. Arrhenius plots were established from these data as shown in Fig. 6. It can be seen again that the initial moisture content of the nut samples did not influence carbon

Fig. 4. Moisture evolution from hazelnuts with

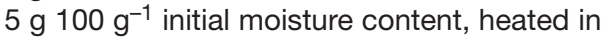
nitrogen and oxygen atmosphere.

dioxide formation to a significant extent, which is due to the fact that decarboxylation takes place after most of the initial moisture has been removed. The activation energy amounted to $82.8 \mathrm{~kJ} \mathrm{~mol}^{-1}$. The reaction rate of decarboxylation at isothermal conditions was found to be constant for at least $10 \mathrm{~min}$ so that a zero order reaction is proposed for decarboxylation by non-enzymatic browning.

From the dynamic DSC experiments with different heating rates under inert conditions, the activation energy of decarboxyla-

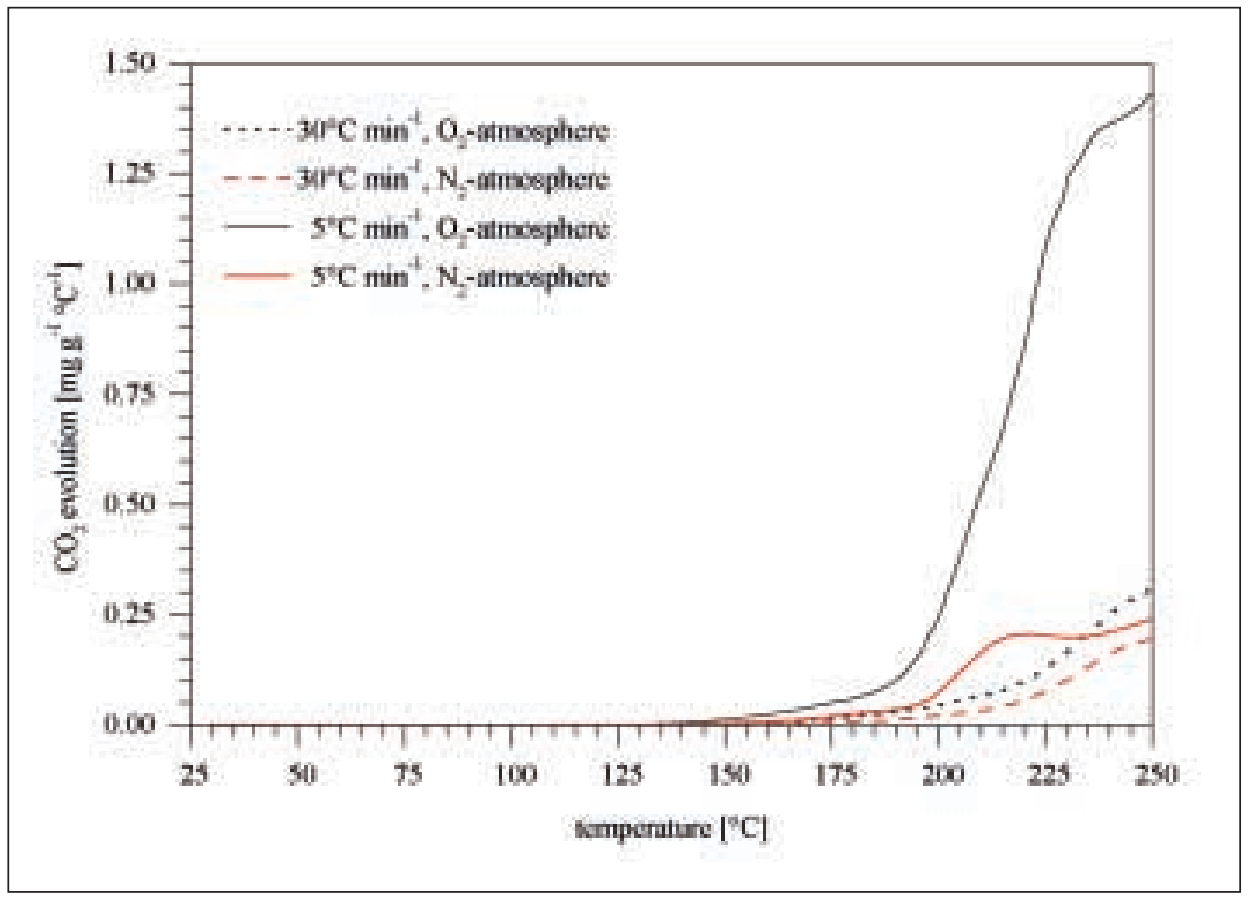

Fig. 5. Evolution of carbon dioxide from hazel-

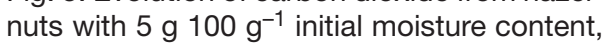
heated in nitrogen and oxygen atmosphere. 


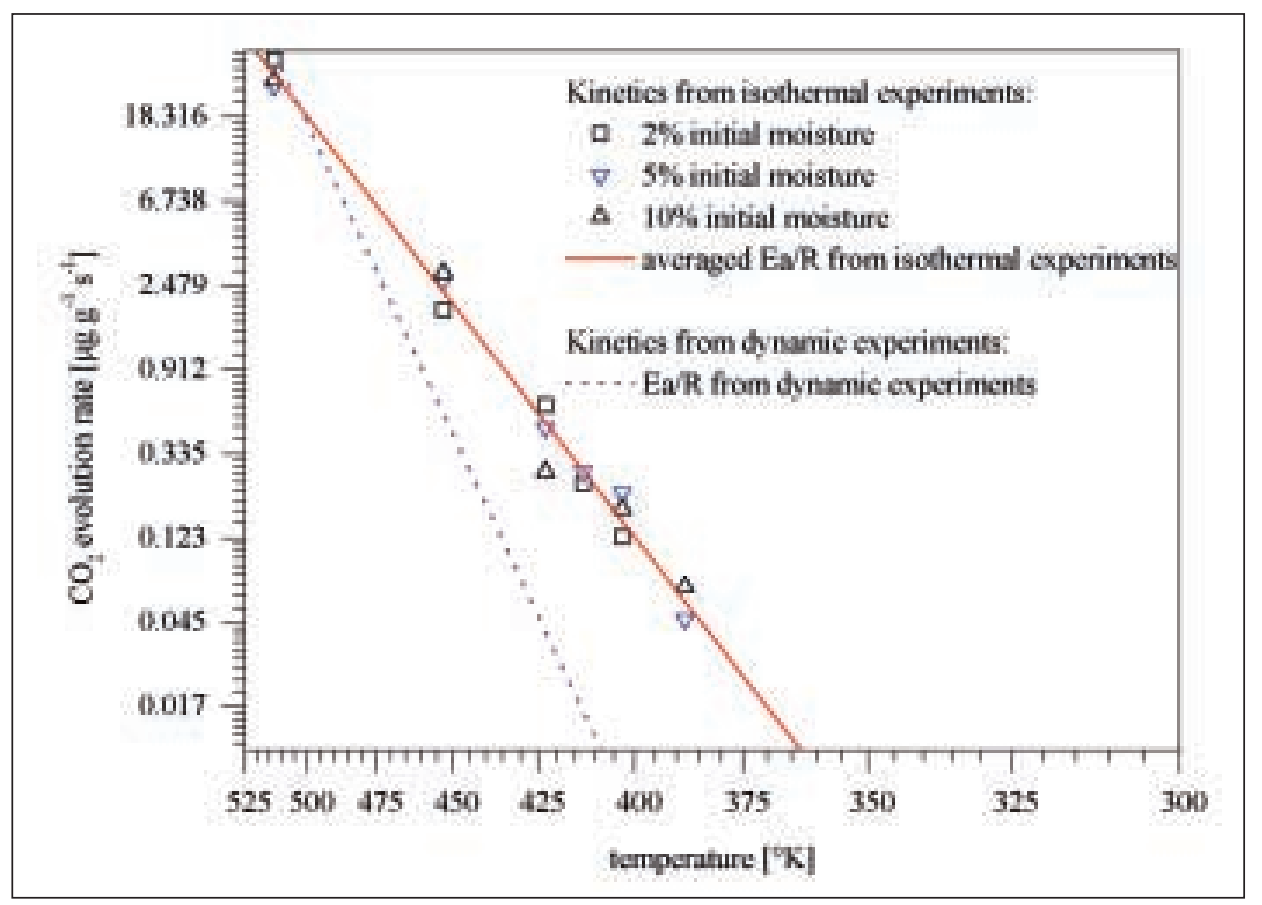

tion was also calculated based on a zero order reaction. Using the approach of Gyulai and Greenhow [10] the activation energy was calculated to be $138 \mathrm{~kJ} \mathrm{~mol}^{-1}$ (Fig. 6).

\section{Conclusions}

Although micro-scale roasting of hazelnuts cannot be translated directly to industrial roasting processes, the influence of heating rate, roasting temperature and composition of roasting atmosphere on browning reactions may nevertheless be assessed, at least in principle. Both differential scanning calorimetry (DSC) as one of the common methods of thermal analysis of foods, and evolved gas analysis based on IR techniques are suitable to follow-up changes in oil-containing nuts during dry heating.

The micro-scale experiments confirm that the heating rate has a major influence on the rate of moisture removal and carbon dioxide formation. At the same time, it is well known that the heating rate influences the extent of changes in the microstructure of nuts, which in turn control oxidative stability at least to some extent [11][12]. The micro-scale experiments also show that lipid oxidation may start already during roasting. Sandmeyer [13] also described accelerated oxidation in hazelnuts that had been roasted at high temperatures.

Once the relative importance of the evolution of water vapour and carbon dioxide is known, the EGA technique provides an interesting tool to monitor overall changes in roasting processes.
[1] G.R. Waller, M.S. Feather (Eds.), 'The Maillard Reaction in Foods and Nutrition', ACS Symposium Series 215, ACS, Washington D.C., 1983.

[2] T.P. Labuza, G.A. Reineccius, V.M. Monnier, J. O'Brien, J.W. Baynes (Eds.), 'Maillard Reactions in Chemistry, Food, and Health', The Royal Society of Chemistry, London, 1994.

[3] E.D. Crnjar, A. Witchwoot, W.W. Nawar, J. Agri. Food Chem., 1981, 29, 39.

[4] C.R. Lerici, D. Barbanti, M. Manzano, S. Cherubin, Lebensmittel-Wissenschaft und -Technologie 1990, 23, 289.

[5] K. Takama, Z. Iseya, S. Sugiury, K. Matsumoto, E. Koahiba, I. Miura, H. Shinano. Bulletin of the Faculty of Fishery, Hokkaido Univ., 1989, 40, 50.

[6] J.O. Lephardt, R.A. Fenner, Appl. Spec. 2000, 34, 174.

[7] D.J. Morgan, J. Thermal Anal. 1977, 12, 245.

[8] M.E. Brown, 'Introduction to thermal analysis' Chapman and Hall, London, 1988.

[9] LI-COR, LI-6262 CO2/H2O 'Analyzer Instruction Manual', Li-Cor Inc., Lincoln, NE, 1990.

[10] G. Gyulai, E.J. Greenhow, J. Thermal Anal. 1974, 6, 279.

[11] C.T. Young, W.E. Schadel, J. Food Sci. 1991, 56, 76.

[12] S. Langourieux, R. Perren, F. Escher, in 'Frontiers in Flavour Science' (Eds. P. Schieberle, K.-H. Engel), Deutsche Forschungsanstalt für Lebensmittelchemie, München, 2000, 527.

[13] D. Sandmeier, Süsswaren 1991, 35, 499.
Fig. 6. Arrhenius plot of the evolution rate of carbon dioxide as determined by isothermal and dynamic heat treatment. 